\title{
A REPERSONALIZAÇ̃̃O DO DIREITO CIVIL A PARTIR DO PRINCÍPIO DA FRATERNIDADE: UM NOVO ENFOQUE PARA TUTELA DA PERSONALIDADE NA CONTEMPORANEIDADE
}

Clara Cardoso Machado Jaborandy" Tatiane Gonçalves Miranda Goldhar**

SUMÁRIO: Introdução; 2 A Repersonalização do direito civil; 3 Da tutela da personalidade na contemporaneidade; 4 A fraternidade enquanto paradigma dos direitos da personalidade; 5 Conclusão; Referências.

RESUMO: O presente artigo tem por objetivo analisar o fenômeno da repersonalização do direito civil a partir do princípio constitucional da fraternidade. Nesse sentido, pretende-se demonstrar que, apesar dos numerosos estudos em torno dos direitos da personalidade, ainda não houve uma real ruptura com a dogmática tradicional, já que a lógica patrimonialista continua a servir de alicerce para estudos que, teoricamente, se referem à proteção da pessoa. Dessa forma, partindo-se da compreensão de que a proteção do ser humano não é tarefa exclusiva do Estado, mas de toda sociedade, existindo uma verdadeira corresponsabilidade, o artigo visa demonstrar a importância da aplicação da fraternidade como instrumento de proteção de direitos de maneira a evidenciar o âmbito de sua aplicabilidade enquanto princípio capaz de redimensionar os direitos da personalidade na contemporaneidade. Como metodologia aplicada à pesquisa, utilizou-se, inicialmente, o método indutivo, alcançando a premissa geral no fenômeno da repersonalização do direito civil, para posteriormente utilizar o método dedutivo e descritivo e assim verificar como o princípio da fraternidade auxilia na tutela dos direitos da personalidade. Quanto aos procedimentos, foram utilizadas as técnicas provenientes dos tipos de pesquisas bibliográfica e documental.

PALAVRAS-CHAVE: Repersonalização; Fraternidade; Direitos da personalidade

\section{THE RE-PERSONALIZATION OF CIVIL RIGHT BY THE PRINCIPLE OF FRATERNIT Y: A NEW FOCUS FOR THE SAFEGUARD OF THE PERSONALITY}

ABSTRACT: The phenomenon of re-personalization in civil law will be investigated through the constitutional principle of fraternity. In spite of several analyses on the

\footnotetext{
Doutora em Direito pela Universidade Federal da Bahia (UFBA). Docente do Mestrado em Direitos Humanos e dos cursos de Graduação e pós graduação da Universidade Tiradentes (UNIT). Brasil.

${ }^{* *}$ Mestre em Direito pela Universidade Federal de Pernambuco (UFPE). Brasil.
} 
rights of the personality, a real rupture with traditional dogma has not occurred. This is due to the fact that patrimonial logic is still the bases for studies which theoretically refer to the protection of the person. Since the protection of the human being is also the task of society and not an exclusive task of the State, within a true stance of co-responsibility, the paper demonstrates the importance of the application of fraternity as a tool for the protection of rights and shows the applicability range as a principle capable of re-sizing the rights of personality. Methodology comprised induction to reach the general premise within the phenomenon of the personalization of civil rights. The deduction method is then used to verify the manner fraternity aids in the tutelage of personality rights. Techniques derived from the types of bibliographic and documental research were also employed.

KEY WORDS: Re-personalization; Fraternity; Rights of the personality.

\section{LA REPERSONALIZACIÓN DEL DERECHO CIVIL A PARTIR DEL PRINCIPIO DELA FRATERNIDAD: UN NUEVO ENFOQUE PARA TUTELA DE LA PERSONALIDAD EN LA CONTEMPORANEIDAD}

RESUMEN: En el presente artículo se tiene por objetivo analizar el fenómeno de la repersonalización del derecho civil a partir del principio constitucional de la fraternidad. En ese sentido, se pretende demostrar que, a pesar de los numerosos estudios en torno de los derechos de la personalidad, aún no hubo una real ruptura con la dogmática tradicional, ya que la lógica patrimonialista sigue a servir de fundamento para estudios que, teóricamente, se refieren a la protección de la persona. De esa forma, partiéndose de la comprensión de que la protección del ser humano no es tarea exclusiva del Estado, sino de toda sociedad, existiendo una verdadera corresponsabilidad, en el artículo se visa demostrar la importancia de la aplicación de la fraternidad como instrumento de protección de derechos de manera a evidenciar el ámbito de su aplicabilidad como principio capaz de redimensionar los derechos de la personalidad en la contemporaneidad. Como metodología aplicada a la investigación, se utilizó, inicialmente, el método inductivo, alcanzando la premisa general en el fenómeno de la repersonalización del derecho civil, para posteriormente utilizar el método deductivo y descriptivo y así verificar como el principio de la fraternidad auxilia en la tutela de los derechos de la personalidad. Cuanto a los procedimientos, se utilizaron las técnicas provenientes de los tipos de investigaciones bibliográfica y documental.

PALABRAS CLAVE: Repersonalización; Fraternidad; Derechos de la personalidad. 


\section{INTRODUÇÃO}

Após um longo período em que o direito civil brasileiro teve enfoque patrimonial, ganha importância no cenário jurídico um movimento que busca valorizar a pessoa humana nos termos da Constituição Federal: o da repersonalização do Direito Civil.

Apesar dos numerosos estudos que versam acerca da tutela da personalidade no campo civilista, ainda não houve uma real ruptura com a dogmática tradicional, de modo que a lógica patrimonialista continua a servir de alicerce para estudos que abordam, ao menos hipoteticamente, os instrumentos de proteção do ser humano, enquanto sujeito de direitos.

Diante disto, pretende-se examinar a correlação existente entre o fenômeno da repersonalização do direito civil e o princípio da fraternidade. Por certo, uma vez reconhecido como princípio jurídico de caráter normativo, a fraternidade tem $o$ condão de ultrapassar a realidade meramente formal, passando à busca da efetividade e concretização dos direitos fundamentais numa perspectiva horizontal.

$\mathrm{Na}$ busca de sistematizar quais são as funções do princípio da fraternidade e sua aplicabilidade no Direito Civil-Constitucional Brasileiro, o artigo procura evidenciar o deslocamento axiológico-interpretativo de direitos de caráter patrimonial para direitos existenciais, de forma a demonstrar a existência de deveres por parte do Estado e da sociedade para efetivação dos direitos da personalidade, a partir da responsabilidade fraternal.

Como metodologia aplicada à pesquisa, utilizou-se, inicialmente, o método indutivo, uma vez que entre as perspectivas de trabalho foram utilizadas: a observação do fenômeno da repersonalização do direito civil e a investigação da tutela da personalidade. Posteriormente, após o encontro da premissa geral, possibilitada pelo método anteriormente descrito, se utilizou o método dedutivo e descritivo, uma vez que o raciocínio parte de uma premissa geral e volta-se para uma situação particular, qual seja, verificar de que forma o princípio da fraternidade pode ser utilizado como paradigma na proteção dos direitos da personalidade.

Quanto aos procedimentos, foram utilizadas as técnicas provenientes dos tipos de pesquisas bibliográfica e documental, visto que foram utilizadas as técnicas de revisão e fichamento bibliográfico/documental. 


\section{A REPERSONALIZAÇÃO DO DIREITO CIVIL}

As profundas transformações sociais exigiram o redimensionamento ético do direito e a releitura de inúmeros institutos jurídicos a partir da Constituição ${ }^{03}$, com o intuito de resgatar o bem central em torno do qual o fenômeno jurídico ganha sentido, qual seja, a valorização do ser humano ${ }^{04}$.

Contudo, no âmbito do "direito privado" 05 a vertente que busca a valorização da pessoa não ocorreu de forma imediata, já que o direito civil continuou pautado em arquétipos dogmáticos ligados ao paradigma patrimonial, principalmente no que tange a interpretação e a aplicação das leis.

A conformação do direito civil à Constituição, também denominado de processo de constitucionalização do direito civil, tem o seu início a partir de 1988, ano do advento da denominada "Constituição Cidadã", por meio da ação de doutrinadores engajados em uma perspectiva de trabalho voltada à percepção do ser humano enquanto sujeito de direitos e deveres na seara civil, a exemplo de Paulo Luiz Netto Lôbo $^{06}$, Gustavo Tepedino ${ }^{07}$, Luiz Edson Fachin ${ }^{08}$, Maria Celina Bodin de Moraes ${ }^{09}$, Giselda Hironaka ${ }^{10}$, Judith Martins-Costa ${ }^{11}$, influenciados, sobretudo, pela doutrina

${ }^{03}$ Ricardo Guastini compreende constitucionalização do ordenamento jurídico como "un proceso de transformación de un ordenamiento al término del cual el ordenamiento en cuestión resulta totalmente impregnado por las normas constitucionales. Un ordenamiento jurídico constitucionalizado se caracteriza por uma Constitución extremadamente invasora, entrometida (pervasiva, invadente), capaz de condicionar tanto la legislación como la jurisprudencia y el estilo doctrinal de los actores políticos, así como las relaciones sociales" (GUASTINI, Ricardo. La constitucionalización del Ordenamiento Jurídico: el caso Italiano. In: CARBONEL, Miguel (org.), Neoconstitucionalismo (s). Madrid: Editorial Trota, 2003, p. 49). Conferir ainda BARROSO, Luís Roberto. Neoconstitucionalismo e constitucionalização do direito: o triunfo tardio do direito constitucional no Brasil. Revista da Escola Nacional da Magistratura, Brasília, v. 1 n. 2, p. 26-72, out. 2006.

${ }^{04}$ Nesse sentido cf. KANT, Immanuel. Fundamentação da Metafísica dos Costumes. In: Os pensadores. Kant (II), Trad. Paulo Quintela. São Paulo: Abril Cultural, 1980; ROCHA, Carmem Lúcia Antunes da. O Princípio da Dignidade da Pessoa Humana e a exclusão social. Revista Interesse Público, n. 4, 1999; SARLET, Ingo Wolfgang. Dignidade da pessoa humana e direitos fundamentais na Constituição Federal de 1998. 6. ed. Porto Alegre: Livraria do Advogado, 2008.

${ }^{05}$ No que tange a superação da dicotomia público-privado, cabe conferir, interessante trabalho, desenvolvido por Tartuce e Opromolla, no qual se defende a superação da referida dicotomia, de modo a apontar a utilidade mínima de ser uma divisão destinada tão somente a fins didáticos. (TARTUCE, Flávio; OPROMOLLA, Márcio Araújo. Direito Civil e Constituição. Constituição Federal - 15 anos. Editora Método. 2003).

${ }^{06}$ LÔBO, Paulo Luiz Netto. Constitucionalização do direito civil. Revista de Informação Legislativa, Brasília, a. 36, n. 141, p. 103, jan./mar. 1999.

${ }^{07}$ TEPEDINO, Gustavo. O Código Civil e o direito civil-constitucional. In: Temas de direito civil, t. II. Rio de Janeiro: Renovar, 2006.

${ }^{08}$ FACHIN, Luiz Edson. "Virada de Copérnico": um convite à reflexão sobre o Direito Civil brasileiro contemporâneo. In: FACHIN, Luiz Edson (Coord.). Repensando Fundamentos do Direito Civil Brasileiro Contemporâneo. Rio de Janeiro: Renovar, 1998, p. 317-324.

${ }^{09}$ BODIN DE MORAES, Maria Celina. A caminho de um direito civil constitucional. In: Revista de Direito Civil, Imobiliário, Agrário e Empresarial, v. 17, n. 65, jul./set. de 1993, pp. 21-32.

${ }^{10}$ HIRONAKA. Giselda Maria Fernandes Novaes. Tendências do Direito Civil no século XXI. In: FREIRE DE SÁ, Maria de Fátima; FIÚZA, César; NAVES, Bruno Torquato de Oliveira. Direito Civil: Atualidades. Belo Horizonte: Del Rey, 2003. p.93-114.

${ }^{11}$ MARTINS-COSTA, Judith. A boa-fé no direito privado. São Paulo: Revista dos Tribunais, 1999. 
estrangeira e Pietro Perlingieri ${ }^{12}$ e Ricardo Luis Lorenzetti ${ }^{13}$, que, em tempo, refletia a influência do movimento constitucionalista nos ordenamentos de seus países.

A constitucionalização do direito civil fez com que o ponto de referência axiológico-interpretativo seja a Constituição. É dizer: mantém-se a autonomia científica do sistema civilista, mas se reconhece que seus postulados, princípios e regras são redimensionados a partir dos valores constitucionais, mormente no que se refere à tutela dos direitos fundamentais.

É nesse espaço que surge o fenômeno da repersonalização do direito, representando uma verdadeira superação do paradigma patrimonialista clássico da pessoa humana que enfatizava os direitos patrimoniais da pessoa, em detrimento da própria pessoa em si mesmo considerada.

Inelutavelmente, é mister ir além dessa perspectiva tradicional, para compreender a pessoa em sua totalidade, mudando-se o eixo valorativo da civilística clássica de cunho patrimonialista ${ }^{14}$ para centrar a atenção na tutela do ser humano ${ }^{15}$.

Seguindo os ensinamentos de Luiz Edson Fachin"16: "Sendo o homem liberdade e criatividade, não pode ele receber do Direito o mesmo tratamento dispensado às coisas. Há que se privilegiar, portanto, uma ideia personalista, que coloque o homem como centro do Direito, em oposição à postura patrimonialista que apresenta a propriedade como o grande centro do interesse da dogmática jurídica".

Especificamente no que concerne à proteção da pessoa, tem-se que o conceito de pessoa deve deixar de ser apenas um sinônimo de capacidade ou personalidade para ser compreendido na sua dimensão existencial concreta. Dito de outra forma, o fundamento do direito civil repersonalizado é a dignidade humana prevista

${ }_{12}$ PERLINGIERI, Pietro. Perfis do direito civil: introdução ao direito civil constitucional. Tradução Maria Cristina De Circo. Rio de Janeiro: Renovar, 2007.

${ }^{13}$ LORENZETTI, Ricardo Luis. Fundamentos do Direito Privado. São Paulo: RT, 1998.

${ }^{14}$ Convém registrar que a despatrimonialização do direito civil não significa a exclusão do conteúdo patrimonial do direito, mas a funcionalização do próprio sistema de modo a respeitar a dignidade humana. Nesse sentido conferir RAMOS, Carmem Lucia Silveira. A constitucionalização do direito privado e a sociedade sem fronteiras. In: FACHIN, Luiz Edson (Coord.). Repensando fundamentos do direito civil contemporâneo. Rio de Janeiro: Renovar, 1998. p. 16.

15 Paulo Luiz Neto Lobo assinala que a "patrimonialização das relações civis que persiste nos códigos, é incompatível com os valores fundados na dignidade da pessoa humana, adotado pelas constituições modernas, inclusive pela brasileira (artigo 1, III). A repersonalização reencontra a trajetória da longa história da emancipação humana, no sentido de repor a pessoa humana como centro do direito civil, passando o patrimônio ao papel de coadjuvante, nem sempre necessário. (...) O desafio que se coloca aos civilistas é a capacidade de ver as pessoas em toda sua dimensão ontológica e, por meio dela, seu patrimônio. Impõe-se a materialização dos sujeitos de direitos, que são mais que apenas titulares de bens. A restauração da primazia da pessoa humana, nas relações civis, é a condição primeira de adequação do direito à realidade e aos fundamentos constitucionais." (LÔBO, Paulo Luiz Netto. Constitucionalização do direito civil. Revista de Informação Legislativa, Brasília, a. 36, n. 141, p. 103, jan./mar. 1999)

${ }^{16}$ FACHIN, Luiz Edson. Estatuto jurídico do patrimônio mínimo. Rio de Janeiro: Renovar, 2001. p. 48. 
no art. $1^{\circ}$, III, CF, que é materializada no âmbito do direito civil, nos direitos da personalidade, compreendidos como condições indispensáveis à própria existência digna da pessoa ${ }^{17}$.

Ocorre que para que o fenômeno da repersonalização possa realmente acontecer, é necessária a efetivação de uma hermenêutica civil-constitucional, adotando-se as noções da constitucionalização do direito civil, que são representadas por uma análise do direito civil a partir de uma filtragem constitucional.

Decerto, a proteção da personalidade não se esgota nos artigos 11 a 21 do Código Civil, existindo, na linha de Gustavo Tepedino, uma verdadeira cláusula geral de tutela da personalidade ${ }^{18}$, uma vez que não se demonstra possível, muito menos viável, prever todos os direitos da personalidade.

Outrossim, há grande aproximação dos direitos da personalidade com os direitos fundamentais insculpidos no texto constitucional, de modo que o livre desenvolvimento da personalidade só ocorrerá com o efetivo respeito aos direitos fundamentais. Nesse sentido, tem-se o enunciado 274 da IV jornada de direito civil: "Os direitos da personalidade, regulados de maneira não-exaustiva pelo Código Civil, são expressões da cláusula geral de tutela da pessoa humana, contida no $\operatorname{art.} 1^{\circ}$, inc. III, da Constituição (princípio da dignidade da pessoa humana). Em caso de colisão entre eles, como nenhum pode sobrelevar os demais, deve-se aplicar a técnica da ponderação".

$\mathrm{Na}$ realidade, a pessoa deve ser protegida em qualquer situação em que se encontre, observando-se assim os dispositivos do texto constitucional que tratam da cidadania, da dignidade humana, da igualdade, da solidariedade e da fraternida$\mathrm{de}^{19}$. De qualquer sorte, a previsão infraconstitucional dos direitos da personalidade

\footnotetext{
${ }^{17}$ Consoante ensinamentos de Pietro Perlingieri: "A personalidade é, portanto, não um direito, mas um valor (o valor fundamental do ordenamento) e está na base de uma série aberta de situações existenciais, nas quais se traduz a sua incessantemente mutável exigência de tutela. Tais situações subjetivas não assumem necessariamente a forma do direito subjetivo e não devem fazer perder de vista a unidade do valor envolvido. Não existe um número fechado de hipóteses tuteladas: tutelado é o valor da pessoa sem limites, salvo aqueles colocados no seu interesse e naqueles de outras pessoas. A elasticidade torna-se instrumento para realizar formas de proteção atípicas, fundadas no interesse à existência e no exercício da vida de relações". PERLINGIERI, Pietro. Perfis do direito civil: introdução ao direito civil constitucional. Rio de Janeiro: Renovar. 1997. p. 155 -156.

${ }^{18}$ Destaca Gustavo Tepedino: "A personalidade humana deve ser considerada antes de tudo um valor jurídico, insuscetível, pois, de redução a uma situação jurídica-tipo ou a um elenco de direitos subjetivos típicos, de modo a se proteger eficaz e efetivamente as múltiplas e renovadas situações em que a pessoa venha a se encontrar, envolta em suas próprias e variadas circunstâncias. Daí resulta que o modelo do direito subjetivo tipificado, adotado pelo Codificador brasileiro, será necessariamente insuficiente para atender às possíveis situações subjetivas em que a personalidade humana reclame tutela jurídica". TEPEDINO, Gustavo. Crise de Fontes Normativas e Técnica Legislativa na Parte Geral do Código Civil de 2002. In: TEPEDINO, Gustavo (coord.). A Parte Geral do Novo Código Civil: Estudos na Perspectiva Civil-Constitucional. Rio de Janeiro: Renovar, 2003, p. XXIII.

${ }^{19}$ No sentido de demonstrar a abrangência que se deve dar à ideia de direitos da personalidade, cabe apontar o enunciado 531 da VI Jornada de Direito Civil, qual seja: "A tutela da dignidade da pessoa humana na sociedade da informação inclui o direito ao esquecimento".
} 
deixou claro que os direitos fundamentais devem ser observados não somente pelo poder público, mas por todos os membros da sociedade civil (eficácia horizontal ou vinculação dos particulares aos direitos fundamentais).

Apesar de terem existido inúmeros questionamentos sobre a vinculação dos indivíduos aos direitos fundamentais, compreende-se que a revolução paradigmática do constitucionalismo contemporâneo não abre mais espaço para incertezas quanto à possibilidade de aplicação direta e imediata dos direitos fundamentais nas relações privadas no ordenamento jurídico brasileiro ${ }^{20}$.

Especificamente em relação aos direitos de personalidade previstos no texto constitucional não se veem óbices à vinculação aos particulares. Ao revés, a corresponsabilidade dos indivíduos e do Estado em relação a estes direitos é crucial para a sua proteção integral. Tanto é verdade que a própria Constituição estabeleceu expressamente direitos e deveres individuais no art. $5^{\circ}$.

Partindo da percepção de que o ser humano só pode ser compreendido em sua dimensão coexistencial ${ }^{21}$ vê-se a importância da aplicação do princípio da fraternidade para a tutela dos direitos da personalidade na medida em que a noção de fraternidade aqui defendida passa pela dimensão intersubjetiva ética compreendendo liberdade, igualdade e fraternidade como condições humanas. Para tanto, faz-se necessário repensar o perfil egoico dos direitos fundamentais incutidos pela tradição iluminista e incorporar na esfera da socialização o caráter fraterno. ${ }^{22}$

\section{DA TUTELA DA PERSONALIDADE NA CONTEMPORANEIDADE}

Os direitos da personalidade formam uma das categorias jurídicas do sistema civilista que mais tem se transformado na atualidade por que dizem respeito às demandas do ser humano em contínua construção.

A personalidade pode ser considerada "como conjunto de características e atributos da pessoa humana, considerada como objeto de proteção por parte do or-

\footnotetext{
${ }^{20}$ Nesse sentido conferir SARMENTO, Daniel. Direitos Fundamentais e Relações Privadas. 2 ed. 3 tir. Rio de Janeiro: Editora Lumen Juris, 2010; CANARIS, Claus-Wilhelm. Direitos Fundamentais e Direito Privado. Tradução: Ingo Wolfgang Sarlet e Paulo Mota Pinto. Coimbra: Almedina, 2006; STEINMETZ, Wilson Antônio. Vinculação dos Particulares a Direitos Fundamentais. São Paulo: Ed. Malheiros, 2005.

${ }^{21}$ Luiz Edson. Estatuto jurídico do patrimônio mínimo. Rio de Janeiro: Renovar, 2001. p. 48-49.

${ }^{22}$ MACHADO, Clara. O princípio jurídico da fraternidade. Rio de Janeiro: Lumen Juris, 2017.
} 
denamento jurídico"23. Assim, é consenso que a personalidade é qualidade própria à condição humana. Ensina Pontes de Miranda ${ }^{24}$ que "o direito de personalidade, os direitos, as pretensões e ações que dele se irradiam são irrenunciáveis, inalienáveis, irrestringíveis. São direitos irradiados dele os de vida, liberdade, saúde (integridade física e psíquica), honra, igualdade".

A partir da Constituição Federal de 1988, conforme acima explanado, momento em que se consagra, teoricamente, a dignidade da pessoa humana como um princípio fundante da ordem jurídica brasileira, irradiando-se para todo o sistema jurídico, observa-se, sobretudo no direito civil, principalmente pela marca histórica que lhe é própria e conhecida de todos nós, um movimento de reestruturação de bases ontológicas que levam ao jurista a um novo olhar e difícil trilhar no que tange ao processo hermenêutico e de proteção jurídica.

Esse caminho não é fácil porquanto redimensionar o cerne de relações jurídicas é ressignificar valores importantes e consolidados para as pessoas de uma dada sociedade, mas ela própria tem exigido da filosofia jurídica e do sistema jurídico esse reconhecimento do SER sobre o TER, afinal o homem e sua dignidade é o porquê e o destino da norma.

O homem do século atual não se realiza mais no seu acervo patrimonial. Todos os institutos patrimoniais do direito civil precisaram passar pelo filtro do valor constitucional para buscar uma função social e destinada a atender os anseios do homem.

Já os direitos da personalidade, por que são inerentes à condição humana passaram pelo filtro do princípio da dignidade da pessoa humana e ganharam uma conotação universalista e embora ainda carentes de materialização constituem hoje um dos mais relevantes ramos de estudo do direito civil, haja vista a necessidade premente atualizá-los frente às demandas da sociedade e dos indivíduos,

Sabe-se que essa força oculta que move o espírito social no sentido de realização das individualidades como resultado de uma busca da própria essência da vida humana em sociedade é apanágio da Declaração Universal dos Direitos do Homem

\footnotetext{
23 TEPEDINO, Gustavo. A Tutela da Personalidade no Ordenamento Civil-constitucional Brasileiro. In: TEPEDINO, Gustavo. Temas de direito civil. Rio de Janeiro: Renovar, 1999. p. 23-54, p. 27.

${ }^{24}$ MIRANDA, Francisco Cavalcanti Pontes de. Tratado de direito privado. Atualização Vilson Rodrigues Alves. 2. ed. Campinas: Bookseller, 2000. Tomo I, p. 216.
} 
de $1948^{25}$, diploma que consagrou, num nível de generalidade e universalidade, os direitos do homem atemporal e geograficamente ilimitado, a resultar em seu irrestrito reconhecimento jurídico da personalidade humana e, mais, a incessante busca pela garantia desses direitos seja qual for o local onde o indivíduo se encontre. É dizer, todo o sistema jurídico, respeitadas as interferências culturais próprias de cada nacionalidade, deve em ultima ratio, buscar resguardar o ser humano de situações que inibam sua formação emocional, espiritual, física e social ou que agridam seus direitos de cidadão universal.

Os direitos do homem ou da personalidade humana são inegavelmente um fenômeno social, de modo que intangibilidade da liberdade, imagem, honra, igualdade entre pares, identificação pessoal, orientação sexual, são produtos dos processos de conquistas e construções da própria sociedade onde o ser está imerso, não se podendo exigir, de forma arbitrária, num plano interno mais do que a sociedade pôde vivenciar em sua história, sob pena de desindentificação do homem com seu sistema jurídico fundante.

$\mathrm{O}$ mesmo raciocínio não se aplica ao direito internacional de modo que à Declaração Universal de que tratamos incumbe o reconhecimento e proteção do homem numa amplitude mais ampla, geral e ilimitada, mas respeitando as vivências de cada nação e povo, auxiliando-os na percepção e assunção desses valores universais, mas acima de tudo respeitando os próprios homens e mulheres partícipes dessa história segmentada nesse ou naquele país.

Eis a grande dificuldade desse diploma normativo: universalizar e desenvolver a proteção quando há ainda realidades abissais no que tange ao reconhecimento do papel do ser humano em cada órbita de vida. O que para a maioria pode ser considerada um contrassenso, como é a escravidão humana na contemporaneidade, um verdadeiro atentado quanto ao direito universal de ir e vir do homem ${ }^{26}$, para algumas culturas, esse ainda é o modo de relacionar com o outro, o outro menor.

A par da nunca exaurida discussão sobre a origem dos direitos da personalidade, se são direitos naturais ou frutos de um reconhecimento jurídico (positivados), é mister curvar-se, na atualidade, ao caráter de inerência humana desses

\footnotetext{
25 "A Declaração Universal dos Direitos do Homem representa a manifestação da única prova através da qual um sistema de valores pode ser considerado humanamente fundado e, portanto, reconhecido: e essa é prova é o consenso geral acerca de sua validade". In BOBIO, Norberto. A era dos direitos. Trad. Celso Nelson Coutinho. Rio de Janeiro, Elsevier, 2004, p. 26.

${ }^{26}$ Art. 40: "Ninguém será mantido em escravidão ou servidão; a escravidão e o tráfico de escravos estão proibidos em todas as suas formas".
} 
direitos eis que ser humano é ser humano em qualquer parte do globo, com muitos dos anseios profundos iguais ou equivalentes a qualquer outro.

É verdade que já não se discute mais a existência desses direitos, pois o problema da hora é a proteção e desenvolvimento deles, de acordo com Norberto Bobbio, nos mais variados sistemas jurídicos tão desiguais quanto às formas de compreender o ser humano e suas necessidades básicas.

Eis por que a categoria dos direitos da personalidade, imanente ao ser humano, tem então vivenciado profundas transformações e sempre haverá de experimentar, sobretudo no que tange ao dimensionamento da responsabilidade civil pela lesão ou ameaça de lesão deles num dado caso concreto.

Como afirma Anderson Shreiber, na obra "Novos paradigmas da responsabilidade civil", o alargamento das responsabilidades individuais e coletivas num nível precedente à lesão, ou seja, pela produção de risco ao próximo, é consequência desse reconhecimento de que há direitos que não podem aguardar a lesão e, no caso de direitos de personalidade, há sentimentos muito caros ao indivíduo que não podem ser ultrajados pelo outro, como é o exemplo do dever de cuidado, apoio moral e afetivo, o qual tem ensejado a responsabilização por abandono afetivo nas relações familiares. ${ }^{27}$

Shreiber, na verdade, coaduna com a ideia de que os interesses existenciais dos indivíduos devem ser tutelados pelo Estado e pelo próximo, num estado de "dever geral de cautela" quando o assunto é o outro, mas que dificuldades práticas exsurgem das problemáticas e dos conflitos de interesses, como se exemplifica na questão da revista íntima em que de um lado tem o dever de oferecer segurança à sociedade ou a coletividade determinada e de outro lado, o direito à intimidade de alguém em negar-se, por exemplo, a ser tocado e revistado, ainda que alguém do mesmo sexo.

Diante disso, nem sempre é fácil a solução, mas não restam dúvidas de que muitas vezes direitos individuais são flexibilizados em prol de interesses que envolvem o número maior de pessoas.

Não se negue, ainda, a força jurídica do reconhecido direito de resistência contra o Poder do Estado, do qual muito comenta Norberto Bobbio ${ }^{28}$, ao afirmar que: "O indivíduo recorre ao direito de resistência como extrema ratio, em última

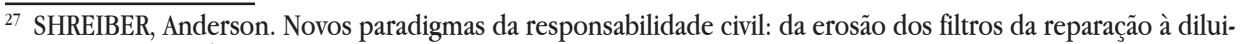
ção dos danos. 6. ed. São Paulo: Atlas, 2015, p. 179-180.

${ }^{28}$ Op cit., p. 113. 
instancia, para se proteger contra a falta de proteção dos direitos primários; portanto, ele não pode ser tutelado, mas deve ser exercido com riscos e perigos para quem o reivindica".

Pode-se concluir que ao embasar as relações jurídicas com o princípio da fraternidade, o qual, frise-se está estampado no art. $1^{\text {o }}$ da Declaração Universal2 ${ }^{29}$, ainda que numa acepção pouco jurídico-normativa e mais imaterial e valorativa, designada que está pela palavra "espírito", naturalmente pode-se permitir o exercício do direito de resistência no âmbito das relações horizontais também e não só indivíduo-Estado.

Se antes buscava o direito de liberdade do indivíduo do jugo do Estado-Absoluto ou até do mais recente pseudodemocrático, hoje se fala em direito de esquecimento, ou seja, o direito que cada a qualquer um não reviver momentos tristes ou dramáticos de sua história, em canais televisivos, mídias sociais e rádios. Ora, quem já cogitou normativamente do direito à memória em alguns casos, o direito de buscar sua origem genética ${ }^{30}$, direito de troca de identicidade civil, a partir ou não da alteração do órgão sexual, entre tantos outros, tão atuais e imprescindíveis quanto o é a necessidade humana de integração e autoconhecimento na evolução da sociedade?

São situações existenciais que estiveram longe dos olhos e mentes mais atentas!

Quanto ao direito de esquecimento, é reconhecido às pessoas o direito de serem esquecidas pela opinião pública e até pela imprensa. Os atos que praticaram no passado distante não podem ecoar para sempre, como se fossem punições eternas. A tese do direito ao esquecimento foi assegurada, há quatro anos, em dois recursos especiais julgados pela $4^{\mathrm{a}}$ Turma do Superior Tribunal de Justiça. As decisões, unânimes, marcam a primeira vez que uma corte superior discute o tema no Brasil.

Os casos decorrem de dois recursos ajuizados contra reportagens da TV Globo, um deles por um dos acusados mais tarde absolvidos pelo episódio que ficou conhecido como a Chacina da Candelária, no Rio de Janeiro. O outro, pela família de Aída Curi, estuprada e morta em 1958 por um grupo de jovens. As demandas foram à Justiça porque os personagens das notícias no caso de Aída, os familiares sentiram

\footnotetext{
${ }^{29}$ Artigo 1: todos os homens nascem livres e iguais em dignidade e direitos. São dotados de razão e consciência e devem agir em relação uns aos outros com espírito de fraternidade.

${ }^{30}$ GOLDHAR, Tatiane Gonçalves Miranda. O Direito à informação e ao conhecimento da origem genética. In: ALBUQUERQUE, Fabíola Santos; et al. (Coord.). Famílias do Direito Contemporâneo: Estudos em homenagem a Paulo Luiz Netto Lôbo. Bahia: Jus Podivm, 2010.
} 
que não havia necessidade de resgatar suas histórias, já que aconteceram há muitos anos e não faziam mais parte do conhecimento comum da população.

Não se olvide que esse direito de personalidade já era reconhecido no Enunciado 531 (A tutela da dignidade da pessoa humana na sociedade da informação inclui o direito ao esquecimento), da VI Jornada de Direito Civil do Conselho da Justiça Federal (CJF), cuja justificativa é que: Os danos provocados pelas novas tecnologias de informação vêm-se acumulando nos dias atuais. $O$ direito ao esquecimento tem sua origem histórica no campo das condenações criminais. Surge como parcela importante do direito do ex-detento à ressocialização. Não atribui a ninguém o direito de apagar fatos ou reescrever a própria história, mas apenas assegura a possibilidade de discutir o uso que é dado aos fatos pretéritos, mais especificamente o modo e a finalidade com que são lembrados.

Destarte, também é dado ao homem na atualidade o direito de resistir a qualquer ato estatal ou privado que ameace ou agrida sua condição humana nos mais variados aspectos do ser, conforme garante, inclusive, nossa Carta Magna de 1988, no rol do extenso e necessário art. $5^{\circ}$.

O direito de resistência não é propriamente um direito de personalidade, mas tem fundamento na agressão ou ameaça a este, de modo que ser exercitável quando o indivíduo sentir-se atentado na sua forma livre de pensar e de agir, dentro dos preceitos e convicções que lhes são próprios. É dizer, trata-se de um direito que exsurge como reconhecimento da intangibilidade do direito de personalidade.

Outro direito sobre o qual tem se produzido bastante é o direito à indenização por abandono afetivo, aqui compreendido como "abandono moral" ${ }^{31}$ No trabalho em que se procurava estabelecer o adequado conteúdo do direito ao afeto, inserido no contexto do direito de personalidade de ser cuidado e amado, dentro de um contexto mais amplo de direito à convivência familiar, mas exteriorizado por condutas objetivas do indivíduo a quem se cobra o exercício e a indenização (dever de educar, cuidar, estar presença, instruir etc.), concluiu-se que o afeto em seu aspecto objetivo pode sim resultar num dano à personalidade do indivíduo que teve negado o direito à convivência filial mínima.

O Superior Tribunal de Justiça, a partir do Resp. 1.159.242/SP, sob a Relatoria da ministra Nancy Andrighi, reconheceu, através de sua terceira turma, a possi-

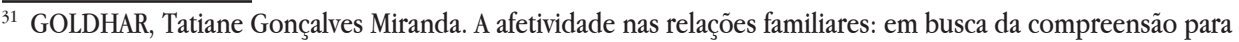
uma tutela jurídica adequada. Atualidades Jurídicas [recurso eletrônico]: Revista do Conselho Federal da Ordem dos Advogados do Brasil - OAB. Belo Horizonte, v. 1, n. 1, jul./dez. 2011. Disponível em: < http://dspace/ xmlui/bitstream/item/13780/PDIexibepdf.pdf?sequence=1>. Acesso em: 30 jul. 2017.
} 
bilidade de compensação por dano moral decorrentes do abandono afetivo, numa clara percepção da sutileza das emoções e da desestruturação psíquica que alguém pode sofrer e padecer durante anos pela ausência de uma conduta adequada em relação aos seus sentimentos e direito à convivência paterno-filial.

Seria inimaginável, por exemplo, o reconhecimento e tutela desse direito há alguns anos atrás se não tivesse havido uma reinterpretação dos direitos da personalidade à luz do princípio da dignidade da pessoa humana e, agora com maior ênfase, do princípio jurídico da fraternidade que só reforça a proteção.

O raciocínio é esclarecido ainda por Paulo Lôbo 32 para quem: "[...] os direitos à vida, à honra, à integridade física, à integridade psíquica, à privacidade, dentre outros e inerentes à pessoa, pois sem eles não se concretiza a dignidade humana. A cada pessoa não é conferido o poder de deles dispor, sob pena de reduzir a sua condição humana; todas as demais pessoas devem abster-se de violá-los".

Não obstante, o primor e a importância de tais direitos, não é demais afirmar que não há defesa aqui de absolutismo do direito da pessoa. Há hipóteses em que, numa pretensa colisão entre direitos fundamentais privados, um direito poderá casuisticamente ser preterido em relação ao outro, devendo haver um juízo de ponderação valorativo do que naquele momento resulta mais importante proteger, o que não permite a conclusão teórica de fragilidade, excepcionalidade dos direitos da personalidade, tampouco se admite a ideia de absolutismo de algum deles, aprioristicamente.

Diante de algumas breves premissas postas, conclui-se que o subsistema constitucional-civil de direitos da personalidade está em constante e, por que não dizer, desafiador crescimento, a demandar do jurista uma abertura hermenêutica nunca antes vista.

$\mathrm{Na}$ era da velocidade, de valores e relações líquidas, conforme bem pontua Zygmunt Bauman ${ }^{33}$, as demandas humanas estão cada vez mais crescentes e carentes, de modo que as relações mais instáveis e susceptíveis de agressões ao outro, no aspecto mais profundo o seu ser, como é o elemento estruturante da personalidade humana, psiquê, identificação de gênero, espiritual, etc. Fala-se, pois, em "cláusula geral da personalidade humana" e não apenas o rol taxativo do art. $5^{\circ} \mathrm{da}$ Constituição ou do art. 11 ao 21 do Código Civil.

$O$ fato de se reconhecer a abertura semântica dos direitos de personalidade não é apanágio para seu não reconhecimento e proteção por parte da ordem jurídica, ao contrário, Paulo Lôbo apregoa que "quando o juiz deparar-se com situação

${ }_{33}$ BAUMAM, Zygmunt. Modernidade Líquida. Rio de Janeiro. Jorge Zahar, 2001. 
fática que nãos e enquadra nos tipos legais de direitos da personalidade, mas que evidencia violação a esta, deve verificar se é cabível, no caso, a tutela do princípio da dignidade da pessoa humana. Essa operação hermenêutica de reenvio ao princípio assegura a plena aplicabilidade dos direitos da personalidade".

É dizer: os direitos da personalidade são fluidos, inesgotáveis e não vinculados aos tipos legais existentes.

A crescente preocupação com o reconhecimento e garantia deles pela ordem jurídica se revela pela recente lei que modificou o art. $3^{\circ}$ do Código Civil, o estatuto das pessoas com deficiência, que é destinada a assegurar e a promover, em condições de igualdade, o exercício dos direitos e das liberdades fundamentais da pessoa com deficiência, visando a sua inclusão social e cidadania. Dentro desses direitos fundamentais estabelecidos pela lei, estão incutidos os direitos da personalidade civil humana, deferíveis na integralidade aos menos favorecidos e em situação de vulnerabilidade.

Pietro Perlingieri ${ }^{34}$ explica esse fenômeno da formação social, como organismos e espaços sociais onde o indivíduo transita e dos quais participa como agentes responsáveis pelo desenvolvimento humano, afinal "a formação social tem valor constitucional somente se atender à função do livre desenvolvimento da pessoa".

Trata-se, pois, de um reconhecimento de que não só o Estado deve tutelar e desenvolver a pessoa humana, por ser esta uma tarefa de todos nós enquanto seres que se relacionam uns com os outros. É, pois, a consolidação da aplicação dos direitos fundamentais nas relações privadas, conforme apregoa Daniel Sarmento. ${ }^{35}$

No que tange à modificação no direito civil, observa-se que, para capacitar ainda mais as pessoas com deficiência e protegê-las, reconhecendo da forma mais ampla possível os direitos de personalidade, o art. $3^{\circ}$ passou a contemplar apenas os menores de 18 anos como incapazes, de modo que todo e qualquer caso de mitigação da consciência, vontade e compreensão será enquadrada como relativamente incapaz, conforme dispõe art. $4^{\circ}$ do diploma civilista.

Tal modificação revela a preocupação do sistema brasileiro em respeitar a vontade humana, os direitos da personalidade, não restringindo tais direitos por obstáculos temporários ou indeterminados da expressão da personalidade humana, garantindo, pois, tutela pelo instituto da assistência jurídica, mas ao mesmo tempo, a intangibilidade dos direitos fundamentais do homem.

\footnotetext{
34 PERLINGIERI, Pietro. Perfis do direito civil: introdução ao direito civil constitucional. 2 ed. Renovar: São Paulo, 2007, p. 39.

35 SARMENTO, Daniel. Direitos Fundamentais e Relações Privadas. 2 ed. 3 tir. Rio de Janeiro: Editora Lumen Juris, 2010.
} 
Nesse contexto, a busca na atualidade é de instrumentos que visem garantir esse reconhecimento e proteção no âmbito das relações privadas principalmente, haja vista que a jornada dessa busca sempre destinou às relações verticais, mas na contemporaneidade é assente a necessidade de uma melhor tutela, com mais qualidade e embasamento no âmbito das relações jurídicas horizontais.

A fraternidade, nesse caminhar, apresenta-se como um pilar estruturante dessa lógica argumentativa em busca de, cada vez mais, tornar o outro responsável pela verdade e pela felicidade do próximo, dentro dos limites das potencialidades de cada ser humano.

\section{A FRATERNIDADE ENQUANTO PARADIGMA DOS DIREITOS DA PERSONALIDADE}

A fraternidade é o novo paradigma dos direitos da personalidade, na medida em que defende o reconhecimento do outro, uma vez que a personalidade é constituída a partir do reconhecimento da dignidade do outro e, com isso, liberdade e igualdade afirmam-se e conquistam-se numa relação de coexistência e interdependência ${ }^{36}$.

De fato, a fraternidade reconstrói, desse modo, o sentido universal da experiência humana nas relações políticas e sociais uma vez que "remete à ideia de um "outro" que não sou eu nem minha esfera social, mas o "diferente" diante do qual tenho deveres e responsabilidades, e não somente direitos a opor" ${ }^{" 37}$. Ao postular o

${ }^{36}$ MACHADO, Clara. O princípio jurídico da fraternidade. Rio de Janeiro: Lumen Juris, 2017.

${ }^{37}$ Sobre o estudo da fraternidade convém conferir no direito estrangeiro: RESTA, Eligio. Il diritto fraterno. 12 ed. Roma: Laterza, 2005. BAGGIO, Antonio Maria (Org.). O Princípio Esquecido/1: A fraternidade na reflexão atual das ciências políticas. Traduções Durval Cordas, Iolanda Gaspar; José Maria de Almeida. Vargem Grande Paulista - SP: Cidade Nova, 2008. BAGGIO, Antonio Maria (Org.). O Princípio Esquecido/2: Exigências, recursos e definições da fraternidade na política. Traduções Durval Cordas, Luciano Menezes Reis. Vargem Grande Paulista - SP: Cidade Nova, 2009. PIZZOLATO, Filippo. Il principio constitucionale di fraternità: intinerario di ricerca a partire dalla Constituzione Italiana . Roma: Città Nuova, 2012. No Brasil, tem-se os ensinamentos de BRITTO, Carlos Ayres. Teoria da Constituição. Rio de Janeiro: Forense, 2003; BRITTO, Carlos Ayres. O humanismo como categoria constitucional. Belo Horizonte: Forum, 2007. MACHADO, Carlos Augusto Alcântara. A garantia constitucional da fraternidade: constitucionalismo fraternal. Tese de doutorado. Pontifícia Universidade Católica de São Paulo. 2014. VIAL, Sandra Regina Martini. Direito fraterno na sociedade cosmopolita. RIPE - Revista do Instituto de Pesquisas e Estudos, Bauru, v. 1, n. 46, p. 119-134, jul./dez. 2006; VIAL, Sandra; ZAMBRANO, Virginia (org.). Salerno: Brunolibri, 2010, p. 71-89. VIAL, Sandra Regina Martini. Saúde: um direito fundado na fraternidade. Saúde e direitos humanos/Ministério da Saúde. Fundação Oswaldo Cruz, Núcleo de Estudos em Direitos Humanos e Saúde Helena Besserman. Ano 5, n. 5 (2008). Brasília: Editora do Ministério da Saúde, 2009. VERONESE, Josiane Rose Petry, OLIVEIRA, Olga Maria B. Aguiar de. Direitos na pós-modernidade: a fraternidade em questão. Florianópolis: Fundação Boiteux, 2011. VERONESE, Josiane Rose Petry, OLIVEIRA, Olga Maria B. Aguiar de. Direito e Fraternidade. Rio de Janeiro: Lumen Juris, 2013. VERONESE, Josiane Rose Petry, OLIVEIRA, Olga Maria B. Aguiar de, OLIVEIRA, Francisco Cardozo. A fraternidade como categoria jurídica: da utopia à realidade. Curitiba: Instituto Memoria. Centro de Estudos da Contemporaneidade, 2015. 
reconhecimento do outro, o enraizamento do indivíduo na comunidade, a responsabilidade individual e estatal, o princípio da fraternidade completa a teoria dos direitos fundamentais, em face da suplantação de construções identitárias de forte raiz liberal para a realização da alteridade. Frise-se que a fraternidade não é filantrópica ou assistencialista, mas possui perspectiva garantista voltada à efetivação de direitos fundamentais e à exigência de deveres.

Da mesma forma, não se deve confundir fraternidade com solidariedade. A solidariedade tem como referência o apoio mútuo dos indivíduos seja na esfera institucional ou social (reconhecimento do outro numa relação de vulnerabilidade ou hipossuficiência), servindo para justificar tanto as políticas intervencionistas do Estado, como também a vinculação dos particulares aos direitos sociais, ao sedimentar a ideia de que cada um de nós é também, de certa forma, responsável pelo bem-estar dos demais. Por sua vez, o centro de referência na fraternidade é a relação intersubjetiva (reconhecimento a partir do outro) marcada por uma relação horizontal e igualitária, que exige dos indivíduos reconhecimento mútuo e responsabilidades comunitárias $^{38}$.

O estudo da fraternidade enquanto princípio jurídico é uma exigência da contemporaneidade em face da constatação da necessidade de uma teoria que se encarregue das lutas por reconhecimento, da afirmação de identidades coletivas e da inclusão do "outro" no Estado democrático de Direito. Esta busca de reconhecimento é mal compreendida, ou mesmo rejeitada, pelos que são inspirados por uma visão solipsista, intelectual e voluntarista da identidade individual, mas encontra respaldo nas sociedades democráticas e no constitucionalismo contemporâneo.

Com efeito, fraternidade é princípio jurídico fundamental que tem, essencialmente, três funções: função de equilíbrio entre liberdade e igualdade, função de reconhecimento e função interpretativa. Enquanto equilíbrio, fraternidade representa o contraponto aos direitos de liberdade e de igualdade, ao evidenciar o lado dos deveres fundamentais, exigindo do indivíduo e do Estado a observância desses deveres, na perspectiva da responsabilidade, a fim de se alcançar o progresso social e incentivar a participação democrática na vida coletiva. A função de reconhecimento explicita a alteridade e a intersubjetividade no direito, impondo-se do sujeito de direito um olhar para o outro, o respeito às diversidades numa sociedade multicultural (processo de inclusão), o espírito de tolerância, de compreensão mútua e de solidariedade. Destaca-se, nesse projeto, a função interpretativa da fraternidade que

\footnotetext{
$\overline{38}$ MACHADO, Clara. O princípio jurídico da fraternidade. Rio de Janeiro: Lumen Juris, 2017, p.107.
} 
deve ser verificada na prática, no momento da definição de sentido de direitos e deveres fundamentais servindo de parâmetro para colisão de diretos fundamentais ${ }^{39}$.

No que tange à colisão entre direitos de personalidade convém relembrar o fato, bastante veiculado nos meios de comunicação, dos impactos causados nos muçulmanos pelo jornal satírico Charlie Hebdo aos que professam a fé islâmica. Apesar de existir uma clara colisão entre liberdade de expressão e liberdade religiosa, a depender da perspectiva do intérprete, o direito que irá prevalecer ao final será distinto, e, consequentemente, repercutirá na tutela dos direitos da personalidade dos que professam a fé ou daqueles que entendem que liberdade de expressão não pode ser limitada sob pena de ofensa ao Estado democrático. A partir do equilíbrio entre liberdade, igualdade e fraternidade, vê-se que, neste caso concreto, não se vislumbra observância da fraternidade no exercício da liberdade de expressão, devendo prevalecer o direito à liberdade religiosa.

No âmbito do Superior Tribunal de Justiça destaca-se a decisão em Recurso Especial $\mathrm{n}^{\mathrm{o}} 1.008 .398$ - SP, que conferiu às pessoas transexuais a possibilidade de alteração do nome no registro civil. Desse modo, entendeu o STJ que, sob o argumento da percepção do "outro eu", insere-se nos direitos da personalidade, em linha com o princípio da dignidade da pessoa humana, a autoafirmação sexual do indivíduo. Ou seja, com o exemplo da aplicação prática, reforça-se a necessidade de discussão do tema aqui proposto ${ }^{40}$.

Com efeito, o princípio da fraternidade exige reconhecimento do outro e responsabilidade em comunidade, servindo de vetor interpretativo na resolução de problemas envolvendo direitos fundamentais.

\section{CONCLUSÃO}

Diante do exposto, alcançam-se as seguintes conclusões:

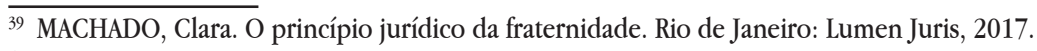

${ }^{40}$ Apesar de não utilizar expressamente o termo "fraternidade" o Superior Tribunal de Justiça utiliza a palavra "hospitalidade": MS 21219 / DF, 2014/0215316-0. Ministro HERMAN BENJAMIN (1132), S1 - PRIMEIRA SEÇÃO, Data do Julgamento 14/12/2016, Data da Publicação/Fonte DJe 02/02/2017; HC 362634 / RJ 2016/0183624-3. Ministra MARIA THEREZA DE ASSIS MOURA (1131), T6 - SEXTA TURMA, Data do Julgamento 16/08/2016, Data da Publicação/Fonte DJe 29/08/2016; AgRg no AREsp 254715 / BA 2012/0237871-7. Ministra MARIA THEREZA DE ASSIS MOURA (1131), T6 - SEXTA TURMA, Data do Julgamento 19/11/2013, Data da Publicação/ Fonte DJe 05/12/2013; RHC 38338 / MA 2013/0176050-4. Ministra MARIA THEREZA DE ASSIS MOURA (1131), T6 - SEXTA TURMA, Data do Julgamento 25/06/2013, Data da Publicação/Fonte DJe 01/08/2013; HC 230028 / PA 2011/0313312-2. inistro SEBASTIÃO REIS JÚNIOR (1148), T6 - SEXTA TURMA, Data do Julgamento 20/06/2013, Data da Publicação/Fonte DJe 01/08/2013.
} 
(1) após um longo período em que o direito civil brasileiro teve enfoque patrimonial, ganha importância no cenário jurídico o movimento da repersonalização do direito civil, que busca valorizar a pessoa humana em sua totalidade;

(2) apesar dos numerosos estudos que versam acerca da tutela da personalidade no campo civilista, vê-se que ainda não houve uma real ruptura com a dogmática tradicional, de modo que a lógica patrimonialista continua a servir de alicerce para estudos que abordam os instrumentos de proteção do ser humano, enquanto sujeito de direitos;

(3) o subsistema constitucional-civil de direitos da personalidade está em constante crescimento, a demandar do jurista uma abertura hermenêutica nunca antes vista;

(4) defende-se, portanto, a correlação existente entre o fenômeno da repersonalização do direito civil e o princípio da fraternidade, na medida em que se constata a necessidade de reconhecimento do outro e a corresponsabilidade dos indivíduos na tutela dos direitos da personalidade;

(5) o princípio jurídico da fraternidade tem o condão de ultrapassar a realidade meramente formal, passando à busca da efetividade e concretização dos direitos da personalidade numa perspectiva horizontal;

(6) a aplicação do princípio da fraternidade no Direito Civil-Constitucional Brasileiro, evidencia o deslocamento axiológico-interpretativo de direitos de caráter patrimonial para direitos existenciais, demonstrando ainda a existência de deveres por parte do Estado e da sociedade para efetivação dos direitos da personalidade, a partir da responsabilidade fraternal.

Como se vê, o tema abordado no artigo comporta inúmeras reflexões que merecem estudos e uma atenção incisiva do direito, na medida em que a tutela integral da personalidade se presta a própria concretização da dignidade.

Para a tutela integral dos direitos da personalidade é essencial compreender e reconhecer a fraternidade enquanto princípio jurídico que resgate a perspectiva dos deveres e assevere a necessidade de reconhecimento do outro. 


\section{REFERÊNCIAS}

BAGGIO, Antonio Maria (Org.). O Princípio Esquecido/1: a fraternidade na reflexão atual das ciências políticas. Traduções Durval Cordas, Iolanda Gaspar; José Maria de Almeida. Vargem Grande Paulista, SP: Cidade Nova, 2008.

BAGGIO, Antonio Maria (Org.). O Princípio Esquecido/2: Exigências, recursos e definições da fraternidade na política. Traduções Durval Cordas, Luciano Menezes Reis. Vargem Grande Paulista, SP: Cidade Nova, 2009.

BARROSO, Luís Roberto. Neoconstitucionalismo e constitucionalização do direito: o triunfo tardio do direito constitucional no Brasil. Revista da Escola Nacional da Magistratura, Brasília, v. 1 n. 2, p. 26-72, out. 2006.

BAUMAM, Zygmunt. Modernidade Líquida. Rio de Janeiro. Jorge Zahar, 2001.

BOBBIO, Norberto. A era dos direitos. Tradução Celso Nelson Coutinho. Rio de Janeiro: Elsevier, 2004. p. 26

BODIN DE MORAES, Maria Celina. A caminho de um direito civil constitucional. In: Revista de Direito Civil, Imobiliário, Agrário e Empresarial, v. 17, n. 65, p. 21-32, jul./set. de 1993.

BRITTO, Carlos Ayres. Teoria da Constituição. Rio de Janeiro: Forense, 2003.

CANARIS, Claus-Wilhelm. Direitos Fundamentais e Direito Privado. Tradução: Ingo Wolfgang Sarlet e Paulo Mota Pinto. Coimbra: Almedina, 2006.

FACHIN, Luiz Edson. "Virada de Copérnico": um convite à reflexão sobre o Direito Civil brasileiro contemporâneo. In: FACHIN, Luiz Edson (Coord.). Repensando Fundamentos do Direito Civil Brasileiro Contemporâneo. Rio de Janeiro: Renovar, 1998.

FACHIN, Luiz Edson. Estatuto jurídico do patrimônio mínimo. Rio de Janeiro: Renovar, 2001.

GOLDHAR, Tatiane Gonçalves Miranda. O Direito à informação e ao conhecimento da origem genética. In: ALBUQUERQUE, Fabíola Santos et al. (Coord.) Famílias do 
Direito Contemporâneo: estudos em homenagem a Paulo Luiz Netto Lôbo. Bahia: Jus Podivm, 2010.

GOLDHAR, Tatiane Gonçalves Miranda. A afetividade nas relações familiares: em busca da compreensão para uma tutela jurídica adequada. Atualidades Jurídicas [recurso eletrônico]: Revista do Conselho Federal da Ordem dos Advogados do Brasil - OAB, Belo Horizonte, v. 1, n. 1, jul./dez. 2011. Disponível em: < http:// dspace/xmlui/bitstream/item/13780/PDIexibepdf.pdf?sequence=1>. Acesso em: 11 nov. 2014.

GUASTINI, Ricardo. La constitucionalización del Ordenamiento Jurídico: el caso Italiano. In: CARBONEL, Miguel (Org.) Neoconstitucionalismo(s). Madrid: Trota, 2003.

HIRONAKA. Giselda Maria Fernandes Novaes. Tendências do Direito Civil no século XXI. In: FREIRE DE SÁ, Maria de Fátima; FIÚZA, César; NAVES, Bruno Torquato de Oliveira. Direito Civil: atualidades. Belo Horizonte: Del Rey, 2003.

KANT, Immanuel. Fundamentação da Metafísica dos Costumes. In: OS PENSADORES. Kant (II), Trad. Paulo Quintela. São Paulo: Abril Cultural, 1980; ROCHA, Carmem Lúcia Antunes da. O Princípio da Dignidade da Pessoa Humana e a exclusão social. Revista Interesse Público, n. 4, 1999.

LÔBO, Paulo Luiz Netto. Constitucionalização do direito civil. Revista de Informação Legislativa, Brasília, a. 36, n. 141, p. 103, jan./mar. 1999.

LÔBO, Paulo. Direito Civil: parte geral. São Paulo, Saraiva, 2009, p. 145

LORENZETTI, Ricardo Luis. Fundamentos do Direito Privado. São Paulo: RT, 1998.

MACHADO, Clara. O princípio jurídico da fraternidade. Rio de Janeiro: Lumen Juris, 2017.

MACHADO, Carlos Augusto Alcântara. A garantia constitucional da fraternidade: constitucionalismo fraternal. Tese (Doutorado) - Pontifícia Universidade Católica de São Paulo, 2014. 
MARTINS-COSTA, Judith. A boa-fé no direito privado. São Paulo: Revista dos Tribunais, 1999.

MIRANDA, Francisco Cavalcanti Pontes de. Tratado de direito privado. Atualização Vilson Rodrigues Alves. 2. ed. Campinas: Bookseller, 2000.

PERLINGIERI, Pietro. Perfis do direito civil: introdução ao direito civil constitucional. Tradução Maria Cristina De Circo. Rio de Janeiro: Renovar, 2007.

PIZZOLATO, Filippo. Il principio constitucionale di fraternità: intinerario di ricerca a partire dalla Constituzione Italiana. Roma: Città Nuova, 2012.

RAMOS, Carmem Lucia Silveira. A constitucionalização do direito privado e a sociedade sem fronteiras. In: FACHIN, Luiz Edson (Coord.). Repensando fundamentos do direito civil contemporâneo. Rio de Janeiro: Renovar, 1998.

RESTA, Eligio. Il diritto fraterno. 12 ed. Roma: Laterza, 2005.

SARLET, Ingo Wolfgang. Dignidade da pessoa humana e direitos fundamentais na Constituição Federal de 1998. 6. ed. Porto Alegre: Livraria do Advogado, 2008.

SARMENTO, Daniel. Direitos Fundamentais e Relações Privadas. 2 ed. 3 tir. Rio de Janeiro: Lumen Juris, 2010.

SHREIBER, Anderson. Novos paradigmas da responsabilidade civil: da erosão dos filtros da reparação à diluição dos danos. 6. ed. São Paulo: Atlas, 2015.

STEINMETZ, Wilson Antônio. Vinculação dos Particulares a Direitos Fundamentais. São Paulo: Malheiros, 2005.

TARTUCE, Flávio; OPROMOLLA, Márcio Araújo. Direito Civil e Constituição. Constituição Federal: 15 anos. São Paulo: Método, 2003.

TEPEDINO, Gustavo. O Código Civil e o direito civil-constitucional. In: TEPEDINO, Gustavo. Temas de direito civil. t. II. Rio de Janeiro: Renovar, 2006.

TEPEDINO, Gustavo. Crise de Fontes Normativas e Técnica Legislativa na Parte Geral do Código Civil de 2002. In: TEPEDINO, Gustavo (Coord.). A Parte Geral do Novo 
Código Civil: Estudos na Perspectiva Civil-Constitucional. Rio de Janeiro: Renovar, 2003.

TEPEDINO, Gustavo. A Tutela da Personalidade no Ordenamento Civil-constitucional Brasileiro. In: TEPEDINO, Gustavo. Temas de direito civil. Rio de Janeiro: Renovar, 1999.

VERONESE, Josiane Rose Petry; OLIVEIRA, Olga Maria B. Aguiar de. Direitos na pósmodernidade: a fraternidade em questão. Florianópolis: Fundação Boiteux, 2011.

VERONESE, Josiane Rose Petry; OLIVEIRA, Olga Maria B. Aguiar de. Direito e Fraternidade. Rio de Janeiro: Lumen Juris, 2013.

VERONESE, Josiane Rose Petry; OLIVEIRA, Olga Maria B. Aguiar de, OLIVEIRA, Francisco Cardozo. A fraternidade como categoria jurídica: da utopia à realidade. Curitiba: Instituto Memoria. Centro de Estudos da Contemporaneidade, 2015.

VIAL, Sandra Regina Martini. Direito fraterno na sociedade cosmopolita. RIPE - Revista do Instituto de Pesquisas e Estudos, Bauru, v. 1, n. 46, p. 119-134, jul./dez. 2006.

VIAL, Sandra; ZAMBRANO, Virginia (Org.). Salerno: Brunolibri, 2010, p. 71-89. VIAL, Sandra Regina Martini. Saúde: um direito fundado na fraternidade. Saúde e direitos humanos. Ministério da Saúde. Fundação Oswaldo Cruz, Núcleo de Estudos em Direitos Humanos e Saúde Helena Besserman. Ano 5, n. 5 (2008). Brasília: Ministério da Saúde, 2009.

Recebido em: 04 de novembro de 2017 Aceito em: 18 de julbo de 2018 